\title{
LA INTERVENCIÓN MILITAR DE LA FACULTAD DE DERECHO: UNA HISTORIA DE RESENTIMIENTO Y COBARDÍA
}

\author{
Pablo Ruiz-Tagle ${ }^{1}$
}

La verdad es que mi familia ya estaba dividida a causa de la reforma agraria y al momento del golpe de Estado de 1973 esas divisiones inevitablemente adquieren nueva fuerza. El 11 de septiembre de 1973 mi barrio se llenó de militares porque vivíamos cerca de la Embajada de Cuba. Cada noche vimos balas trazadoras, se alumbró nuestra casa con las luces de los helicópteros y se instaló una ametralladora punto cinco en la esquina. Fueron días de adrenalina y terror. Nosotros cubrimos las ventanas de mi casa con colchones y muebles pesados para evitar que una bala loca pudiese impactarnos. El mismo día 11 mis padres nos reunieron en la cocina para decirnos que no debíamos decir nada a los vecinos, ni a los militares, sobre las personas de izquierda que conocíamos, que podían ser arrestados o algo peor.

A pesar que yo tenía catorce años en 1973 recuerdo ese día como si fuese hoy. También recuerdo el impacto de los años grises de la dictadura que le siguieron. Mis vecinos eran el gran escritor comunista y amigo de mi padre Francisco Coloane, su señora Eliana y familia. Otro vecino era de la Unidad Popular y trabajaba como interventor estatal de la Empresa Comercializadora de Alimentos, y un agricultor de extrema derecha entre otras personas que no recuerdo. Recuerdo que visité a la familia Coloane en su casa para ver si necesitaban algo y vi al vecino interventor partidario de la Unidad Popular, con gafas oscuras, pasearse frente a su casa con una Biblia recién comprada. También vi al vecino agricultor y muchos otros, vistiendo uniformes militares viejos para celebrar el Golpe.

Finalizados mis estudios en el colegio, y al momento de decidir dónde postular a la Universidad, para informarme y por recomendación de mis padres, llamé por teléfono al historiador Gonzalo Vial, que me aseguró que la Universidad de Chile era la mejor del país. Dijo que era más grande y diversa y uno podía estudiar historia o literatura, incluso durante las horas de clases (aburridas) por la amplitud de sus aulas. También conversé con Fernando Silva, que un tanto renuente recomendó la Universidad de Chile, más que la Católica, a pesar de afirmar que en su opinión en ambas la enseñanza era de muy mala calidad. Ante mis inclinaciones filosóficas, otras personas me recomendaron estudiar Derecho, porque las facultades de filosofía habían sido diezmadas por la dictadura, y en Derecho podían mantenerse ciertas formas académicas.

1. Profesor titular de la Facultad de Derecho, Universidad de Chile. En este trabajo participaron en la búsqueda de documentos los ayudantes Camilo Cornejo, Melissa Linderos, Cristina Duran y Francisca Barra. 
Así las cosas, el año 1977 ingresé como alumno a la Facultad de Derecho de la Universidad de Chile. Durante la dictadura la historia de la facultad fue la de sus decanos². Se habían suprimido todos los entes colegiados de la Universidad y las autoridades unipersonales de los rectores-delegados-militares, y los decanos designados por estos, tenían plenos poderes en la institución universitaria.

Al momento de ingresar a la facultad muchos, yo diría la mayoría (también en el país) se declaraban "juntistas" fundados en el Acuerdo de la Cámara de Diputados y los oficios de la Corte Suprema dirigidos al Presidente Salvador Allende. Esta posición implicaba legitimar el Golpe, pero no necesariamente las violaciones de los derechos humanos, respecto de los cuales muchos decían que debía hacerse la vista gorda por un tiempo o pensaban que fundaban una crítica exagerada a la necesaria intervención de los militares. Otros eran derechamente pinochetistas o fascistas. La oposición a la dictadura, que no llegaba a ser más de un tercio, era clandestina e ilegal y duramente reprimida.

El mismo año 1977 de mi ingreso a la Universidad había asumido por designación de la dictadura militar el decano Hugo Rosende. El ambiente de la facultad estaba marcado por el autoritarismo, la delación y la sospecha. Rosende pidió a los alumnos, en su primera reunión con mi curso, que asistieran a la facultad con chaqueta y corbata y a las alumnas con falda o vestido. Publicó una resolución con esa exigencia en la puerta de la escuela, medida que obviamente nunca pudo hacer cumplir.

En esos años, el profesor Antonio Bascuñán, que también había sido designado decano por la dictadura durante el período que va desde 1974 a 1976, representaba dentro de la facultad una oposición al decano Rosende. Fui alumno en primer año en el curso del profesor Bascuñán, una cátedra que ofrecía una perspectiva "académica" del Derecho y que se dividía en tres materias principales. La primera, inspirada en la obra de Hans Nawiasky, se refería al estudio de las normas jurídicas; la segunda, con gran influencia de Hans Kelsen, se refería al estudio del sistema jurídico; y la tercera, orientada a la explicación del Derecho positivo chileno, trataba las fuentes del Derecho y una referencia general a la ética profesional del abogado en nuestro país. Al término del curso el profesor Bascuñán preguntó a los alumnos qué sugerencias críticas podían hacerse a su cátedra. Recuerdo que junto con agradecerle su trabajo académico y solicitar que pudiese integrarme a su grupo de ayudantes, le comenté que yo pensaba que debían mostrarse otras formas de entender el Derecho, y no solo fundar toda la explicación de un modo predominante en la obra de Hans Kelsen.

El estudio del Derecho con una inspiración académica ya ocupaba buena parte de mis intereses. Una visión crítica del ambiente que me tocó vivir en la facultad se describe de manera magistral en la novela Santiago cero de mi amigo Carlos Franz, que dice:

Las clases del último curso habian comenzado a mediados de marzo. Durante los siguientes dos meses asististe con una dedicación furiosa. Parecía que iban a responderse las plegarias

2. Ver lista de los decanos de la Facultad de Derecho y rectores de la Universidad de Chile al final de este trabajo. 
que elevaba tu madre desde Calama, donde había conseguido trabajo después de enviudar. "Una profesión es un seguro de vida mijito", te escribía, "termínala y después...". Pero a ti, aún sentado en la primera fila de las gélidas aulas y diciendo "Presente" en todas las listas, te era imposible sintonizar las monótonas transmisiones de los profesores. Un chisporroteo constante de emisoras lejanas, en idiomas inciertos, interfería tu cabeza poniéndola en onda corta. Delante pontificaba un académico sin que pudieras entenderle una sola cita ${ }^{3}$.

Al momento de mi ingreso a la facultad ya se habían exonerado casi media centena de profesores, de un total de entre cien a doscientos académicos, y sus nombres y fechas de despido son muy variados, tal como consta en los listados adjuntos al final de este trabajo ${ }^{4}$. Se vivía un ambiente de temor que fue poco a poco cambiando cuando surgieron las primeras manifestaciones contrarias a la dictadura. Recuerdo que la primera manifestación se organizó en torno a una declaración contra el dictador Somoza, que obviamente evocaba una crítica indirecta a Pinochet. Mi amigo y compañero de curso Guillermo Pickering leyó un texto rodeado por alumnos más altos, para que no pudiesen fotografiarlo o grabarlo. Su acción ilegal implicaba la expulsión de la Universidad y entre los auxiliares y alumnos de la facultad existían delatores.

Esa quizás fue la primera manifestación contra la dictadura en la Universidad, pero en ningún caso fue la última. En otra manifestación del año 1978 Guillermo Pickering, Eduardo Saffirio y Gabriel Ascensio salieron a la calle con un lienzo y fueron descubiertos y suspendidos de clases por tres meses. Desde el Ministerio del Interior pidieron su expulsión, pero la medida de suspensión adoptada por el decano Rosende los salvó de la exoneración de la Universidad.

Al conocer esta medida, junto con varios compañeros de curso escribimos una carta al decano Rosende para que revocara la medida de suspensión, lo que no sucedió. Teodoro Ribera, también compañero de curso y representante de la extrema derecha, argumentó en contra del envío de la carta al decano. Según Ribera, la autoridad ya había manifestado su negativa a modificar su decisión y por eso no correspondía insistir con la carta. Estas posiciones las discutimos abiertamente en una asamblea de curso inolvidable, y finalmente 37 alumnos de un total de 150 firmamos la carta pidiendo la revocación de la medida, que no fue acogida.

También a partir de 1978 nos comenzamos a reunir con Miguel Luis Amunátegui, Ricardo Ferrada, Francisco Gazmuri, Juan Ignacio Correa y Emilio Cousiño, entre otros, en las oficinas profesionales de Antonio Bascuñán. En la facultad no nos dieron acceso a ninguna sala y por eso tuvimos que leer en forma privada, en esos días de oscuridad, la obra de Hans Kelsen, Alf Ross y Karl Olivecrona. Luego de su llegada de Alemania se incorporó a este grupo Enrique Barros y leímos la obra de H.L.A. Hart. Enrique sugirió también leer a Arnold Gehlen, F.A. Hayek y Konrad Lorenz, entre otros.

3. Franz, C., Santiago cero, Santiago de Chile: Seix Barral, Biblioteca Breve, 1997 [primera edición, 1989].

4. Ver lista de académicos de la Facultad de Derecho de la Universidad de Chile exonerados con su cargo y la fecha de la medida al final de este trabajo. 
Desde principios de 1979 comenzaron a funcionar de manera organizada y abierta los partidos y fuerzas políticas en la facultad. Hugo Rosende había sido propuesto por Jaime Guzmán para ocupar el cargo de decano, pero al poco tiempo rompió con el gremialismo transformándose en uno de los más importantes partidarios de la dictadura. Prohibió el ingreso de los gremialistas a la facultad y dejo funcionar abiertamente los partidos y fuerzas políticas dentro del recinto universitario con el compromiso que no hicieran manifestaciones contra el Gobierno en el exterior. Rosende había sido un viejo político de la derecha "alessandrista" y gozaba con el micromundo político que el mismo toleraba. La Democracia Cristiana elegía sus directivas votando con una urna abiertamente en el casino de la facultad y los socialistas, comunistas y otros grupos realizaban sus actividades en quizás el único lugar del país que admitía la política permitida por el decano Rosende. El centro de alumnos, que en verdad no tuvo representación democrática sino hasta las elecciones de principios de los años 80, tenía como dirigente designado por la dictadura a Fernando Barros Tocornal, que luego, por la acción de Rosende, fue cambiado por Alberto Espina Otero, quien representaba una posición de apoyo a la dictadura más cercana a las autoridades que no eran gremialistas. En esos tiempos conocí las diversas fuerzas y organizaciones políticas e incluso, junto con Marcelo Moretic, Jaime del Solar y otros alumnos de cursos superiores, tratamos de formar un grupo nuevo que denominamos los "suizos" por nuestra intención de alejarnos y declararnos neutrales respecto de las fuerzas que en esos tiempos se enfrentaban en la lucha fratricida de la política universitaria. Este esfuerzo no tuvo ningún éxito y perdimos todas las elecciones de dirigentes estudiantiles en las que nos presentamos. Finalmente la mayoría de los así denominados "suizos" terminaron en la Democracia Cristiana, la social democracia, el Partido Socialista o seguimos como independientes, como es el caso del suscrito. Fuimos ingenuos de nuestra parte al querer, desde nuestra Facultad, formar algo nuevo, en el clima polarizado y violento que vivía nuestro país.

Este clima se manifestaba por ejemplo en el acto nazista que se realizaba todos los años en la forma de una asamblea en el patio de la facultad, en que un grupo de fachos vestidos de negro y con bototos milicos saludaba Heil Hitler en recuerdo de la matanza del seguro obrero, y gritaba consignas amenazantes. Además se escuchaban rumores de alumnos desaparecidos de la facultad, personas de cuya memoria hay una placa cerca de la pileta, y las historias de torturados y detenidos que sumaban cada día más y más personas en todo Chile también afectaban a muchos de nuestros compañeros.

A finales de 1979, con un grupo de compañeros de curso, creamos una publicación denominada Revista de Ideas Universidad y acción. Nos inspiramos en la lectura de los escritos de Vicente Huidobro y otros intelectuales y juristas para demandar más libertad universitaria y política. Llegamos a tener solo tres números y luego nos enfrascamos en discusiones bizantinas y en un proceso desgastador de autocrítica, para darle continuidad a la mejor forma de dar a conocer nuestras ideas.

Queríamos ser un espacio de libertad en esos tiempos de apagón cultural, resentimiento anti-intelectual y cobardía, donde campeaban los falsos académicos y las acciones de renuncia y silencio de personas entradas por la ventana como profesores y alumnos, en virtud del amiguismo fascista que evocaba la novela Bulevares periféricos de Patrick Modiano, 
que da cuenta del efímero momento de gloria de un picante grupo de intelectuales colaboracionistas de segunda durante la ocupación alemana nazi en Paris.

Nosotros no queríamos tener vínculo alguno con los falsos intelectuales y profesores que nos rodeaban, y a pesar que nuestros puntos de vista y trabajos eran bien pedantes e inexpertos, logramos concitar la atención de las autoridades de la facultad, que más de una vez nos citaron para llamarnos la atención.

Fue en todo caso un imperativo buscar actividades académicas fuera de la facultad por el carácter viscoso, ambiguo y profesional gana pan que caracterizaba nuestra enseñanza universitaria. Eran los tiempos en que rectores militares resentidos, exhibiendo toda clase de sentimientos anti-universitarios, demostraban sus "habilidades" saltando en paracaídas en el campus de Agronomía, como lo hizo Alejandro Medina Lois en un incidente acrobático de triste y vergonzante memoria.

En esos años asistí a las conferencias de Charles Taylor organizadas por Carlos Ruiz Schneider y Renato Cristi, ambos profesores exonerados de la Universidad de Chile y que trabajaban en la Academia de Humanismo Cristiano. Fui a las clases de filosofía que dictó Jorge Millas, otro profesor que había dejado de hacer clases en la facultad y que ahora enseñaba en forma privada en su casa una visión crítica de la obra de F.A. Hayek, que ya se instalaba como padre del neoliberalismo chileno.

La insatisfacción con el clima autoritario de la facultad alimentó las ganas de preparar una reunión de alumnos al término de nuestro período de cursos universitarios. Ya a esas alturas estábamos hastiados de tantas evasivas y en mejor posición de juzgar lo que había sido nuestra (de)formación. En agosto del año 1982 nos reunimos cerca de cincuenta alumnos en la Academia de Humanismo Cristiano y discutimos con pasión durante todo un día.

Allí me tocó presentar un escrito denominado "Proposición", en el que daba cuenta de lo que pensábamos de nuestra facultad. En ese escrito refería no solo a las falencias académicas sino también a problemas extra-académicos que nos afectaban, tales como la necesidad de terminar con la intervención militar de las universidades y las autoridades designadas; solicitar la rendición de cuentas de los recursos públicos universitarios; luchar por la derogación del IVA en los libros; exigir la terminación de los trámites que los estudiantes debíamos realizar en los cantones de reclutamiento; exigir la mejora de la biblioteca, entre otras medidas 5 .

Este documento sirvió para preparar un petitorio que fue suscrito a las pocas semanas por más de seiscientos alumnos de la facultad, y que implicó la furia inicial del decano Rosende y sus aduladores. Se inició contra sus autores, entre los que me encontraba junto con mi amigo Alfredo Jocelyn-Holt, un sumario en Casa Central con amenazas de expulsión o cancelación de matrícula. Paradojalmente, mientras todos los pateros de las autoridades universitarias hablaban de nosotros como si fuésemos delincuentes, pedimos directamente una audiencia con el decano Rosende, y para nuestra sorpresa nos recibió. Enojado al comienzo de nuestra conversación, cambió totalmente de ánimo cuando le hicimos ver que en la biblioteca la situación era tan pobre que no tenía ni

5. Ver documento "Proposiciones" con su formato original como anexo de este artículo. 
siquiera una copia de su memoria de prueba. Al comienzo se manifestó incrédulo de esta carencia, circunstancia que nosotros previamente habíamos revisado en el fichero bibliográfico. Hizo llamar delante de nosotros a la bibliotecaria y le pidió por teléfono que trajeran a su vista su memoria de prueba, lo que no fue posible y que le significó a la pobre funcionaria responsable de cuidar los libros de la facultad recibir las iras del decano y más de una amenaza de despido.

Hugo Rosende había estudiado en la Universidad Católica y por eso no era raro que su memoria no estuviese disponible en nuestra biblioteca. Sin embargo, la sorpresa de esta falta y su vanidad herida lo hizo cambiar de actitud hacia nosotros. Nos terminó ofreciendo en la misma audiencia nombrarnos ayudantes, a lo que no accedimos.

Al final de mi carrera, trabajé con Enrique Barros en mi memoria de prueba sobre la teoría de la justicia de John Rawls, que luego fue publicada en la forma de una síntesis y como artículo en la revista del Centro de Estudios Públicos ${ }^{6}$. Recuerdo también esos años haber discutido muchas veces con Enrique Barros acerca del artículo 8 de la Constitución, que estuvo vigente hasta 1989 y que prohibía el pluralismo ideológico y condenaba el marxismo en la política chilena. Yo siempre critiqué esta norma, que me parecía una reedición de la Ley Maldita, porque pensaba que en Chile no podía excluirse políticamente a personas de la talla de Pablo Neruda o Francisco Coloane. Sobre esta cuestión logré publicar un artículo denominado "Debate público restringido en Chile 1980-1988" en la Universidad Católica, con Jaime Guzmán todavía vivo, a instancias de José Luis Cea, que en ese tiempo era editor de la revista pontificia ${ }^{\top}$.

En 1988, al regreso de mis estudios de Magíster en la Universidad de Yale, dicté mi primer curso de Introducción al Derecho en una Universidad privada porque no me era permitido enseñar en la facultad, donde no se abrían concursos ni se aceptaba el ingreso de ninguna persona que no fuese de la total confianza del régimen.

En la Universidad privada comencé a preparar mis apuntes de clases para su publicación y me propuse criticar la visión "monofónica" que identificaba toda la teoría del Derecho con la obra de Hans Kelsen. El libro, que se dio a conocer con el título Revisión Crítica del Derecho, junto con explicar las ideas de Jeremy Bentham, John Austin, H.L.A. Hart y Ronald Dworkin sobre el sistema jurídico, incluyó además secciones dedicadas a la ciencia del Derecho, explicaciones fundadas en el análisis económico del Derecho y los estudios legales críticos hasta entonces desconocidos en Chile. Concluía con una sección final sobre el iusnaturalismo y el positivismo jurídico

También en los años 80, a partir del texto constitucional que impuso Pinochet en un plebiscito fraudulento, voté nulo. Ya antes había anulado mi voto en la consulta pinochetista contra las Naciones Unidas y el 5 de octubre de 1988 vote "NO" para dar paso a la imperfecta democracia que existe en Chile desde marzo de 1990 hasta nuestros días.

6. Ver Ruiz-Tagle, P., "La prioridad del derecho sobre el concepto moral del bien en la teoría de la justicia de John Rawls", en Revista de Estudios Públicos, V35, Centro de Estudios Públicos, págs. 147-167, 1989.

7. Ver Ruiz-Tagle, P., "Debate público restringido en Chile (1980-1988)", en Revista Chilena de Derecho, V16, Universidad Católica de Chile, págs. 111-129, (1989). 
Recuerdo también que a principios de los años 90 asistí a una conferencia donde se trató la cuestión de la desobediencia civil planteada por la acción valiente del Obispo Valech de negarse a entregar las fichas de la Vicaría de la Solidaridad pedidas por una orden del funesto fiscal militar Torres Silva, fiscal que luego fue paradojalmente condenado por obstrucción a la justicia o un delito semejante. En esos años, al mismo tiempo que admirábamos la decisión del Obispo Valech, discutíamos sobre las consecuencias legales de su decisión fundada en sus potestades de derecho canónico y en la objeción de conciencia ${ }^{8}$.

Durante mi época de estudiante, e incluso más tarde, nunca me terminó de persuadir la idea de militar en un partido político, y a pesar de la propaganda de la dictadura tampoco me terminaron de convencer las justificaciones del golpe de Estado, ni menos la fuerza emergente del pinochetismo gremialista, con su mentiroso discurso antipolítico. En el ambiente enrarecido de la facultad y la Universidad, en que reinaba un resentimiento anti-intelectual y cultural y la expresión más diversa de las formas de la cobardía, me sentía más atraído por el trabajo académico y profesional. Yo pienso que no se trataba de una simple forma de escapismo, sino de tener un poco de tiempo para reflexionar durante mi vida universitaria y de preparar mi vida futura como profesor de la facultad.

Nunca he pensado que mi conducta haya sido plenamente razonada y justificada, ni tampoco me he presentado ante mis semejantes como un modelo desde un punto de vista político y ético. Ahora que pienso en esos tiempos sin las urgencias, ni los miedos de entonces, concluyo que pude haber hecho mucho más por la democracia y por los derechos humanos. Reconozco que quizás me equivoqué en no haber participado en política de manera más activa contra los horrores de la dictadura y también en otras cosas.

Puede ser que muchas personas tengan objeciones respecto de mi forma personalísima de entender los fenómenos jurídicos y políticos, y también de describir y evaluar la influencia de la dictadura militar en la Facultad de Derecho de la Universidad de Chile. Se trata de un juicio parcial que no pretende ofender ni menoscabar a persona alguna y menos todavía erigirse como monopolista de la conciencia pública. Si en algo he ofendido con la expresión de mis ideas o con mi conducta a alguna persona, pido de antemano mis excusas.

Advierto sin embargo la necesidad de enfrentar la acuciante pregunta que nos queda para el futuro, que vuelve una y otra vez a plantearse y de la cual no he encontrado respuesta: ¿si acaso los tiempos tan feos de Pinochet pueden volver a repetirse? Desgraciadamente tengo que reconocer que es posible volver a esos tiempos calamitosos y dictatoriales, porque el germen del resentimiento cultivado en los "ecos de declamaciones oscuras" que denunciaba en 1839 Andrés Bello todavía está muy vigentes en Chile.

Los militares siguen aislados, envidiosos y resentidos, y sospechan del mundo civil, de su libertad, de sus recursos, de sus formas culturales, de sus intelectuales y de todas las formas de su civilización.

8. Ver críticas en Ruiz-Tagle, P., "Enrique Barros: Derecho y Moral; Antonio Bascuñán: Derecho y Moral; Agustín Squella; Derecho y Moral. ¿Tenemos Obligación de Obedecer el Derecho?, en 8 Anuario De Filosofía Jurídica y Social, 1989, págs. 477-481. 
Los capitanes de industria, que ahora muchas veces aparecen vestidos de uniforme militar jugando a la guerra, como dueños de universidades o académicos impostores, comparten con los militares las formas de resentimiento anti-intelectual y anticivilizatorio, y miran el pensamiento crítico y la educación como un bien de consumo que se transa y se compra.

Los civiles y la mayoría de nuestros compatriotas tenemos todavía pendiente la tarea de mirarnos, quizás de "admirarnos" con respeto y dignidad y de imaginar un país sin odio incubado, que pueda terminar con la plaga de cobardes y "pálidos calumniadores", tales como esos a los que se refería Vicente Huidobro. Tenemos que construir por delante un proyecto común más grande que todo el período de la dictadura y más grande también que el de la venganza revanchista de las personas que fueron víctimas en los tiempos de Pinochet. Tenemos que trabajar para construir un proyecto fundado en la justicia, la verdad y la memoria.

Ese proyecto puede quizás gestarse en torno a la construcción de una Nueva Constitución para Chile, la Constitución del Bicentenario. Un proyecto en el que podemos estar todos y todas comprometidos porque creemos que se puede encontrar un nuevo sentido de patriotismo constitucional, en el que toda la ciudadanía chilena se siente orgullosa de vivir en un sistema con instituciones decentes y justas que aseguren libertad, igualdad, dignidad y democracia. Un sistema respecto del cual todos sienten apego, porque a todos acoge.

Se trata de un proyecto ambicioso que tiene el enorme mérito de permitirnos dejar atrás todo vestigio de resentimiento y de ayudarnos a superar las sutiles disquisiciones en que se encapsuló la cobardía durante la dictadura y que todavía persiste y contamina nuestra vida pública.

Agradezco entonces a todos los lectores pacientes de estas líneas, con las que he querido compartir una muestra parcial de algunas de las contradicciones que me ha tocado vivir entre el pensamiento y la acción, en tiempos muy difíciles de la historia universitaria de nuestra querida Facultad de Derecho de la Universidad de Chile.

DECANOS FACULTAD DE DERECHO UNIVERSIDAD DE CHILE PERÍODO 1972 -1990

1. Máximo Pacheco Gómez (1972-1974)

2. Antonio Bascuñán Valdés (1974-1976)

3. Hugo Rosende Subiabre (1976-1983)

4. Avelino León Hurtado (1983-1984)

5. Rafael Eyzaguirre Echeverría (1984-1986)

6. Mario Mosquera Ruiz (1986-1987)

7. Jorge Hübner Gallo (s) (1987)

8. Juan Colombo Campbell (1987-1990) 


\section{NÓMINA DE ACADÉMICOS EXONERADOS DE LA FACULTAD DE DERECHO}

\begin{tabular}{|c|c|c|c|}
\hline & NOMBRE & $\begin{array}{c}\text { AÑO DE } \\
\text { EXONERACIÓN }\end{array}$ & CARGO \\
\hline 1 & AHUMADA PACHECO MIGUEL & 1973 & PROFESOR \\
\hline 2 & BALBONTÍN ARTEAGA LUIS IGNACIO & 1976 & PROFESOR ORDINARIO \\
\hline 3 & BORQUEZ BUSTAMANTE HUGO MARIO & 1974 & PROFESOR TITULAR \\
\hline 4 & BUSTOS RAMIREZ JUAN JOSÉ & 1973 & PROFESOR TITULAR \\
\hline 5 & CÁCERES RUBIO GUILLERMO & 1973 & AYUDANTE INVESTIGADOR \\
\hline 6 & CARRASCO VÁSQUEZ CARLOS & 1976 & ACADÉMICO J/C \\
\hline 7 & CARRASCO VÁSQUEZ JORGE EDUARDO & 1975 & ACADÉMICO M/J \\
\hline 8 & CHADWICK WEINSTEIN TOMÁS & - & PROFESOR AGREGADO \\
\hline 9 & CROXATO DUQUE MARCELO JOSÉ & 1976 & ACADÉMICO J/C \\
\hline 10 & DEPUJADAS HERMOSILLAS GABRIEL & 1976 & PROFESOR SOCIOLOGÍA \\
\hline 11 & ESPINOZA VALLEDOR JOSÉ & 1973 & $\begin{array}{l}\text { INVESTIGADOR Y PROFESOR } \\
\text { AGREGADO }\end{array}$ \\
\hline 12 & FORTÍN CABEZAS CARLOS & 1973 & PROFESOR \\
\hline 13 & FRIEDMAN VOLASKY LORELEY & 1973 & INVESTIGADOR DIRECTO \\
\hline 14 & GARAY PEREIRA JULIO ROBERTO & 1975 & ACADÉMICO J/C \\
\hline 15 & GEISSE GRAEPP FRANCISCO & 1973 & PROFESOR AUXILIAR \\
\hline 16 & GONZÁLEZ POBLETE ALEJANDRO & 1976 & PROFESOR DERECHO \\
\hline 17 & HOECKER PIZARRO MARIA LORETO & 1974 & INVESTIGADOR JEFE \\
\hline 18 & JARA MIRANDA EDUARDO & 1974 & PROFESOR \\
\hline 19 & KOHAN FERNANDEZ ADRIANA & 1973 & AYUDANTE INVESTIGADOR \\
\hline 20 & LÓPEZ HUCKE EDMUNDO & 1976 & ACADÉMICO M/J \\
\hline 21 & LUCERO CONUS SERGIO & 1973 & PROFESOR SUBROGANTE \\
\hline 22 & MANCILLA BETTI JOSE EDUARDO & 1976 & ACADÉMICO SECRETARIO \\
\hline 23 & MEDINA QUIROGA CECILIA & 1973 & PROFESOR AGREGADO \\
\hline 24 & MENA VERGARA VÍCTOR SERGIO & - & PROFESOR AYUDANTE \\
\hline 25 & MERA FIGUEROA JORGE ALEJANDRO & 1976 & ACADÉMICO J/C \\
\hline 26 & MUÑOZ PEÑAILILLO NORMA ELIANA & 1973 & INVESTIGADOR \\
\hline 27 & NAZAR CONTRERAS VÍCTOR & 1976 & ACADÉMICO \\
\hline 28 & NOVOA MONREAL EDUARDO & 1973 & PROFESOR \\
\hline 29 & ORELLANA VARGAS VÍCTOR & 1973 & PROFESOR TITULAR CATEDRAL \\
\hline 30 & ORTIZ ROMERO GUILLERMO EDUARDO & 1973 & PROFESOR INVESTIGADOR \\
\hline 31 & PEREIRA ANABALÓN HUGO & - & PROFESOR DERECHO \\
\hline 32 & POLITOFF LIFSCHITZ SERGIO & 1973 & PROFESOR \\
\hline 33 & POLLACK ESKENAZI BENNY & 1973 & PROFESOR INVESTIGADOR \\
\hline
\end{tabular}




$\begin{array}{ll}34 & \text { QUINZIO FIGUEIREDO JORGE MARIO } \\ 35 & \text { RAMÍREZ NECOCHEA HÉCTOR MARIO } \\ 36 & \text { ROJAS BESOAIN MARIO OLGA } \\ 37 & \text { SALAS SALAS RICARDO ARTURO } \\ 38 & \text { SAN MIGUEL BELTRÁN JAVIER } \\ 39 & \text { SOUPER RODRÍGUEZ JUAN CARLOS } \\ 40 & \text { SZCZARANSKI CERDA CLARA } \\ 41 & \text { TAPIA VALDÉS JORGE ANTONIO } \\ 42 & \text { TESTA ARUESTE ENRIQUE } \\ 43 & \text { UGARTE SOTO CARLOS ADRIANO } \\ 44 & \text { VALDERRAMA PERGOLESSI RICARDO } \\ 45 & \text { VILLALBA GONZÁLEZ HERNÁN } \\ 46 & \text { WOOD SÁNCHEZ ELSIE }\end{array}$

$\begin{array}{cl}1975 & \text { PROFESOR TITULAR } \\ 1975 & \text { PROFESOR M/J } \\ 1976 & \text { ACADÉMICO J/C } \\ 1973 & \text { SECRETARIO DE ESTUDIOS } \\ - & \text { PROFESOR INVESTIGADOR } \\ 1974 & \text { AYUDANTE } 1^{\circ} \\ 1973 & \text { ASESOR IRA. CATEGORÍA } \\ 1973 & \text { PROFESOR } \\ 1975 & \text { PROFESOR ORDINARIO DERECHO } \\ 1976 & \text { PROFESOR } \\ 1977 & \text { ACADÉMICO M/J } \\ 1973 & \text { CONTRATADO DOCENTE } \\ 1974 & \text { PROFESOR INVESTIGADOR }\end{array}$


Sería bueno que cada uno de nosotros para conocerse más a si mismo y darse mejor a conocer a los demas, hiciera aunque fuese en silencio un poco de historia personal de su paso por la universidad.

Mi propia reflexión personal, sobre los motivos que en 1977 me llevaron a postular a la carrera de Derecho, se pueden resumir en especialmente los que siguen: 1) Pensaba ingresar a la facultad donde el pensamiento humanista se desarollaba mejor y en forma más rigurosa en nuestro país. Así accedería a la discusión de los grandes temas. 2) Pensaba adquirir un método sólido de investigación y d sciplina intelectual.3) Pensaba en tercer término tener acceso a los elementos que eventualmente me permitirían ejercer la profesión de abogado en cualquiera de sus variedades.

Pienso que estos mótivos indujeron a gran parte de los alumnos de mejor calidad que tuve la oportunidad de conocer en mis cinco años de estudio.

Lo más triste es que fuera de esporádicos profesores, no pude encontra satisfacción a mis objetivos netamente universitarios. Así fue como comenzó la larga historia de mi desilusión, de mi desencantamiento, de 1 alejarme cada vez más de las aulas de la facultad.

Pero esto no fue un fenómeno aislado, en 1978, con muchos amigos desde los más encontrados puntos de vista, comenzamos a proponer cambios en la facultad. Comenzamos a Iuchar por una Universidad responsable, donde se abriera paso a la discusión y al estudio en forma seria y actualizada, por una uni versidad independiente de camarillas, sectas y gobiernos que terminara con las autoridades designadas y que se llamara a concurso como base de la carrer académica. Además proponíamos que tanto profesores como alumnos, dedicaran pa te importante de su tiempo a la elaboración de investigaciones, monografías y seminarios, exigiéndole permanecer más horas en la Universidad.

Contra una serie impresionante de obstáculos, fundamos la única revista joven que enthuestro país reun distintos puntos de vista, y que a pesar de nuestras limitaciones, se hace con verdad e independencia logrando un nivel bastante aceptable. Nuestra revista fue el refugio de la disidencia, todos los que la formámos coincidíamos en la urgencia de pensar por escrito en completa libertad.

Así con grandes dificultades fuimos capaces en los años 1979 y 1982 catat: 3 números, reunieno un sínnúmero de excelentes trabajos, muchos de los cuales tenían como tema nuestra formación universitaria. Muchas veces fuimos incompi didos, se nos intento etiquetar de muy variadas formas, $y$ todo esto porque no: cabíamos dentro de las esquemas mezquinos de los que jugaban a las componende

Nuetra labor ha sido honrada. Qesde 1978 ante la desastrosal formación universitaria no hemos optado por la aleanza incondicional, ni por el dogma ni por la apatía, hemos optada por la crítica. Siempre hemos optado por la cu tica abierta, franca y directarmpremos que es la unica posibilidad consecuent

Fexo tengan por ciertovque siempre que como hay, exista la posibilidac verdadera de un encuentro de puntos de vista diferentes, estaremos prontos a abandonar nuestro desencantamiento, y nos integraremos gustosos a la liber: y a la racionalidad.

2) IIMITACIONES QUE A MI JUICIO PROVOCA IA ACTUAL FORMACION UNIVERSITARIA EN NUE STRA FORMA DE RACIONALIDAD.

No quiero detenerme esta vez en la detallada descripción de los vicic. que caracterizan nuestra formación universitaria, creo que otros pueden hace: lo mucho mejor que yo, en cambio voy a destacar ciertas limitaciones que se introducen en nuestra forma de pensar por los defectos de nuestra educación. Debemos procurar la autoconciencia de estas limitaciones mentales sobretodo a la hora de pensar en mejores sistemas y planes de estudio. Todos en alguna u otra medida sufrimos de estas taras que paso a caracterizar como siguen:

1) Enfasis en la expresión oral más que en la escrita.

Por el hecho de que el sistema de estudio se basa en la clase magistr. y la forma de control más importante es el examen oral, el estudiante de der cho y todo aquel queppasa por la escuela desarolla más la aptitud de expresí oral que la escrita.

De este modo el estudiante se acostumbra a opinar sobre todo sin toma le $e l$ peso a lo que dice y sin rigor, quedándose sin desarollar la capacidad de expresión escrita que es mucho más necesaria en el procedimiento judicial chileno, y en el trámite de las grandes empresas y en el estado. 
2) Actitud de Anti-admiración. 2) Actitud de Anti-amir dificultad que normalmente supone para una persona
nebido a la mer el desarolio de la expresión oral, el aprendizaje de el estudiante de derecho es muy răpido. En el primer semestra de la carrera este se adapta a los moldes de su carrera. Este desarollo es prematuro si comparamos al estudiante de derecho con cualquier otro estudiante de otra carrera universitarii Esto produce una deformación muy grande es exradicada de la mentalidar jurídica la reflexióm, todo es subjetivo, se admira más la apriencia que el contenido. Además se aprenden una serie de "mañas" para hablar de algo sin saber y sin querer hacerlo, escuchando las interminables y reiterqtorias cla ses margithales.

Muy pronto el estudiante de derecho asume una actitud de envejecimien: espiritual, que le impide adquixir el hábito científico de admirarse ante lo problemas, ante los interrogantes. El lo sabe todo, o por lo menos sabe todo los trucos que le permiten aparentar que lo sabe todo.

3) El Dogmatismo como forma de pensamiento.

EI modo de enseñanza dogmatico basado en la clase magistral, donde se exponen conceptos, que se definen y de los cuales de derivan características y elementos, clasificaciones y jerarquizaciones, aleja nuestro modo de pensa de mecanismos críticos de verificación científica. Nos alejamos de la realid Del téxto de derecho positivo, a la definición, de la definición a los elementos, a la clasificación y los efectos, pero todo esto camino se re liza en un mundo ideal, en el que el unico dato real en que se apoya es el texto de derecho positivo (que en cualquier momento es derogado). Así nuestr pseudo-ciencia juridica se apoya en madera agusanada, se deroga día a día a si misma.

¿Que espacio tiene la vida efectiva del derecho en nuestra ensenanza?

Debemos luchar contra el dogma y apoyamuestra discusión cientifica en ciertos métodos sometidosa discusión y a autoconciencia.dPor qué seguir con procedimientos de aprendizaje dogmáticos?

4) Sistema de conceptos "vigentes" A-historicos A-científicos.

Los conceptos que se tranmiten en forma dogmática inducen al alumno y al profesor a pensar todas las ideas en términos de pensamiento o ideas vige te o derogado. Las ideas son despojadas de su peso verdadero, valen o existe si alguien con poder es capaz de imponerlas. Sólo se piensa se discute lo qu de alguna manera se encuentra reafirmado por un poder.

A modo de ejemplo se puede decir que nunca se analizan las ideas lega les según los motivos históricos que las hicieron nacer, ni según los intere economicos que involucran, ni según la forma en que influyen en nuestra form de actuar y de pensar, tampoco se analizan ni las sentencias ni ninguna mani festación jurídica desde estos múltiples puntos de vista.

Así las ideas sólo se discuten en forma en su relación de fuerza, haciendo impredecibles construcciones que justifiquen estas relaciones arbitra rias de poder en que se encuentran inexplicablemente insertas. De este modo se empobrecen nuestros puntos de vista, nuestro sistema de ideas es cada día más miope.

\section{5) Pensamiento parcelado, atomizado o celular.}

Todos estos conceptos mentales antes descritos se encuentran en un es tado de esteril aislamiento uno del otro, cada uno vive fundamentado en el $t$ to positivo en pequeñas esferas solitarias que permanecen flotando hasta el momento en que debido a una pequeña frase del legisladort fas hace estallar y se hunden en el oceano de la ambiguedad como islas volcánicas.

Los únicos que son capaces de conocer estos conceptos y relacionarlos entre si son una casta de "vacas sagradas" de "iniciados", que por medio de piruetas y magias de todo tipo, todas ellas alejadas del procedimiento cient fico, hacen en forma pirotécnica y devmalabarismo arbitrariotirrepruducible preciosas constreciones mentales de pocos minutos de duración.

En estas efímeras construcciones mentales nunca cabe el sentido del humor ni menos la ironía, ni la historia, ni la ciencia, poselutorma por una se rie de sucesiones de elementos o características que se repiten en diferente conceptos. Es hablando en términos figurado, como una visita turística a este islas en que se encuentran los conceptos, que se realiza sin orden alguno $y$ con el sólo objeto de encontrar a cualquier precio factores comunes.

\section{6) Esquizofrenia Profesional Intelectual.}

en El criterio "calvinista" o de ética protestante que opera en la escut ge que al profesor de mérito o al açdemico de valor, Dios o el Estado debe 
premiarlo con un desempeño profesional exitoso, especialmente en términos pecuniarios, trae consigo otra estructura mental que es falsa, que se nos impone y que altera nuestra manera de pensar.

El estudiante de Derecho piensa que la verdad y el proceso del conocimiento debe desarollarse con miras exclusivamente prácticas. Ia verdad las ideas no valen por si mismas, sino en cuanto me sirven en mi desempeño profesional.

Así la enseñanza y el conocimiento se reducen a una especie de aprendizaje de recetas de cocina, el Derecho se reduce a formulas, el Derecho es Derecho Formulario. Los profesores se tranforman en iniciados de estas formulas Los alumnos discuten sobre que profesor tiene más méritos y conoce más mecanismos secretos de hacerse rico y poderoso.

Es decir todo esto lleva a la construcción de una larga genealogía de vacas sagradas, un verdadero sistema de sectas de adulación sucesiva. Este es el ambiente universitario de nuestra facultad, donde la modestia, la base del connocimiento/queda desterrada en la lucha por el exito y el poder

Por un lado se habla de Dios, por el otro del legislador, ambos seres inaccesibles a la experiencia, sólo una casta privilegiada de teólogos o de juristas es mediadora de las revelaciones de estos seres. Amabas castas con la mentira de querer explicar la voluntad de estos seres, afirman en realidad lo que la voluntad de ellos mismos y sus limitaciones los llevan a pensar que es el Derecho.

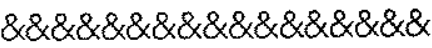

Resumiendo, nuestra formación nos hace valorar/la palbra oral que la reflexión escrita, no nos lleva a una sana actitud de admiración, nos mantenemos en un modelo de pensamiento dogrático, parcelado, atomizado, empobrecido, donde predomina una'concepción practica de la verdad que lleva implicita la formación de sectas de adulación que nada tienen que ver con la universidad.

\section{\&\&\&\&\&\&\&\&\&\&\&\&\&\&\&\&\&\&}

\section{SOLUCIONES QUE SE PROPONEN}

1) En el estudiante de derecho deben desarollarse especialmente las capacidades de razonamiento, negociación, defensa y consejo, planificación e interpretación y aplicación de la ley positiva. Estas aptitudes deben desarollarse preferentemente en la forma de expresión por escrito.

Debe dársele mayor importancia a la lectura(Jurisprudencia, obras Clásicas) y a la elaboración de trabajos por escrito como monografías, por lo menos un trabajo escrito anual o un control de lectura anual por ramo. Ios trabajos deben dar paso a la discusion a la investigación.

En base a estos mismo trabajo deben programarse seminarios, a lo menos uno por departamento y que los alumnos lostomen con consecuencias academicas por lo menos una vez durante la carrera.

2) Debe existir un plan básico y una posibilidad amplia de optar en un curriculum flexible. A modo de ejemplo práctico se puede pedir que todos los ramos que no van incluidosen el examen de Licenciatura pueden considerarse en mayor o menor medida como integrando este curriculum flexible.

Así los abogados se especializan en ciertas materias y tienen en la primera etaja de la carrexa la formación jurídica básica. Este curriculum flexible debe aplicarse por lo menos a partir de tercer año de la carrera.

3) Debe promoverse dentro de los cursosel mayor estudio de la doctrina y de la jurisprudencia para ampliar el horizonte del normativismo imperante. Se podría considerar un trabjo de Biblioteca ciertas tardes de la semana para los alumnos de los cursos de los primerosaños que no pueden trabajar todavía

5) Los curso5y los programas deben dividirse de acuerdo a materias y no de acuerdo a los códigos o Leyes que regulan estas materias. Sobretodo en el último tiempo se han dictado Leyes Miscelaneas y la certheza jurídica es mínima por lo que es conveniente este tipo de enfoque en el estudio.

Ademas debe evitarse con la mala costumbre de la rotación de profemores por los distintos años de la carrera. Los profesores deben ser especialistas en su materia y dedicarse a lo sumo al estudio de dos o tres problemas o materias concretas. 
5.) Hay que pedir un impulso general y exigir mas tanto a profesores como a alumos para que en forma seria se hagan publicacones en los diferentes f temas de interes jurídico. Así y sólo así se desarolla el pensamiento.

6) Crear un sistema claro y programado de formación de ayudantes en todos - los departamentos, con cursos de perfeccionamiento, publicaciones y posibi-

\section{\&\&\&\&\&\&\&\&\&\&\&\&\&\&\&\&\&}

Resumiendo hay que pedir más enfasis en la lectura de textos y en la realizacion de trabajos de investigación, curriculum flexible en gran parte de la carrera, dedicación más completa a la universidad en los primeros ar̃os, estudio de la jurisprudencia y de la doctrina, que los cursos sean enfoacados desde el punto de vista de problemas y materias y no del derecho positivo, que se termine con la rotativa de los profesores, que se publiquen trabajos en nuestra escuela, y que efxista la formación de la geneación de reemplazo.

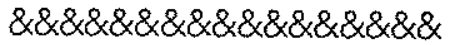

\section{PROBIEMAS EXTRA-ACADEMICOS QUE NOS AFECTAN.}

Quiero terminar haciendo presente una serie de problemas no directamente academicos pero que influyen en nuestra formación universitaria y a los cuales los estudiantes universitarios libres y responsables debemos enfrex tar con soluciones. Aquí van algumas proposiciones de solucioń:

1)El termino de la intervención militar de las universidades y la salida paulatina de todas las autoridades designadas, los universitarios deben autogo-

2) Pedir la creación de un sistema de rendición de cuentas anual o semestral en que las autoridades universitarias (RECTor, Decanos) den cuenta de en que se han invertido nuestros aranceles y cuales son los objetivos futuros. 3) Iuchar por la derogación del IVA a los libres que encarece nuestros textos de estudio y por la derogación de la censura previa de las publicaciones que coarta el pensamiento libre en nuestro país.

4) Exigir el término de todos los trámites hunillantes que todos los estudiantes varones debemos cumplir en los cantones de reclutamiento. Deberíamos proponer un sistema de postergación a través de la Facultad, que no nos hiciera perder tiempo y gastar dinero todos los años. Morgue $\mathrm{Ni}$ los librosse sienten cómodos en ella. Además esta atraøda, los librc de calidad permanecen en manos de las dacas sagradas, y los trámites son espar tosos.

\section{$\& \& \& \& \& \& \& \& \& \& \& \& \& \& \& \& \& \&$}

Nuestra lucha no tendrá exito de un día para otro debemos ser pacientes perseverantes, nuestra responsabilidad no podemos evadirla, no podemos esconde nuestra cara en los grupos, Nuestra responsabilidad es personal.

Debemos luchar todos los diás cada uno de nosotros en forma personal para hacer una Universidad mejor, así poco a poco la acción individual se va reproduciendo en padrones, en actitudes comunes, que producen el efecto global que se necesitaba como origen del cambio. 